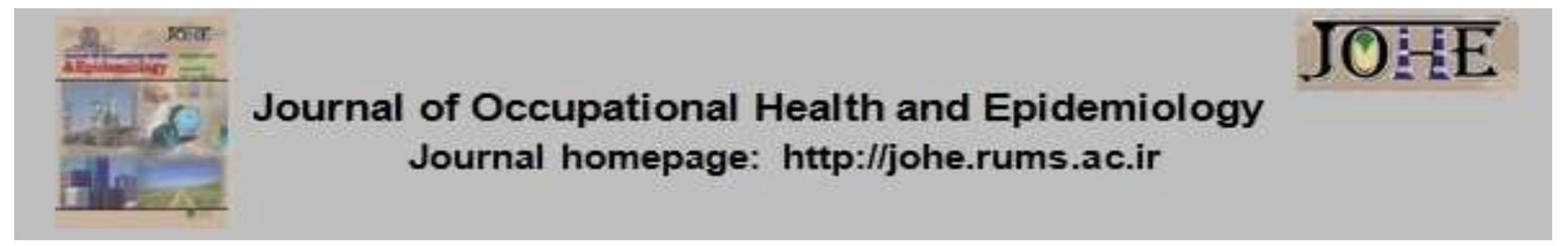

\title{
Structural modeling of career and organizational consequences of psychological empowerment among faculty members of Islamic Azad University in West Azerbaijan Province, Iran, (2017)
}

\author{
Amir Hemmati ${ }^{1}$, Behnam Talebi² ${ }^{*}$, Jahangir Yari Haj Atalou², Mohammad Hassani ${ }^{3}$ \\ 1- PhD Student in Educational Administration, Department of Educational Sciences, Tabriz Branch, Islamic Azad University, Tabriz, \\ Iran. \\ 2- Assistant Prof., Department of Educational Sciences, Tabriz Branch, Islamic Azad University, Tabriz, Iran. \\ 3- Professor, Department of Educational Sciences, Faculty of Literature and Humanities, Urmia University, Urmia, Iran.
}

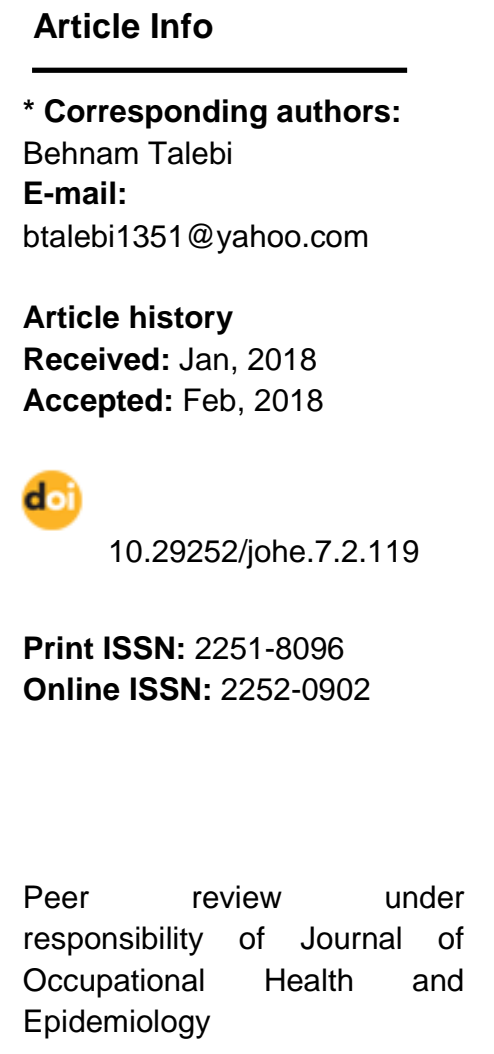

\begin{abstract}
Background: One of the key factors in the effectiveness of universities is faculty members. Paying attention to this important source brings the university closer to its goals. This study aimed to investigate job and organizational consequences of psychological empowerment with mediating role of organizational innovation, organizational justice, and organizational support among in the branches of Islamic Azad University in West Azerbaijan Province, Iran, in year 2017.

Materials and Methods: In this descriptive correlational study, from 747 faculty members in Islamic Azad University of West Azerbaijan, 300 were selected using stratified random sampling method by Morgan table. Data were collected using nine standard questionnaires and a researcher-made questionnaire, and analyzed using SPSS and Lizrel software. Besides, to examine the relationships between latent and measured variables in the conceptual model, the structural equation modeling was used.

Results: Psychological empowerment had positive and significant correlation with citizenship behavior $(r=0.52)$, organizational commitment $(r=0.37)$, job satisfaction $(r=$ $0.34)$, and job performance $(r=0.33)$, and negative and significant correlation with turnover intention $(r=-0.24)$ and absenteeism $(r=-0.31)(P<0.05$ for all).

Conclusion: This research showed that, the highest correlation was found between faculty members' psychological empowerment with organizational citizenship behavior, and the lowest correlation was between psychological empowerment and their turnover intention. In addition, justice, support, and organizational innovation play mediating role in the relationship between psychological empowerment and occupational and organizational consequences.
\end{abstract}

Keywords: Psychological, Empowerment, Job Performance, Absenteeism, Iran.

\section{Introduction}

The core capital of each organization is the human resources of that organization. On the other hand, widespread changes in the current hastily world, emergence in new technologies, and rapid growth of science emphasize the need for accountability for the quality of services provided to stakeholders. Findings of the research on the factors affecting the productivity of universities showed that faculty members' performance lonely explained $30 \%$ of productivity variance, which indicates the critical position of faculty members in achieving university success. Considering the importance of the matter, the need for the empowerment of faculty members, as one of the main solutions to enhance professional and cognitive competencies, is 
inevitable (1). However, Iran's higher education has not been able to succeed in empowering faculty members; as some scholars in the country's higher education have noted it as the crisis of science or the crisis of higher education. This crisis refers to the lack of inconformity of the government investment in the sector higher education with the rate of social and economic returns. (2-3)

The concept of empowerment has come from two main perspectives: socio-structural and psychological. Socio-structural perspectives build empowerment through focusing on an organization formal control sets such as job dimensions, team design, or organizational mechanisms that trigger situations, policies, and procedures (4). On the contrary, the psychological perspective, firstly introduced by Conger and Kanungo (1988), focuses on the employees perceptions of empowerment (5-7). Hence, Thomas and Velthouse (1990) and Spreitzer (1995) argue that multidimensional cognitive factors build meaning, choice, competence, and impact as a set of inner motivations. These four dimensions reflect the active, rather than passive, orientation of the work roles (8). Empowerment has been studied in relation to various variables. Based on scientific researches, empowering the human resources can lead to the promotion of citizenship behavior ( 9 , $10)$, organizational commitment enhancement (11, 12), promotion of job performance (13), promotion of job satisfaction $(14,15)$, and the reduction of turnover intention and absenteeism $(16,17)$.

One of the variables which has attracted the researchers' attention is the concept of organizational support. Perceived organizational support is the general faith of employees including the perceptions of employees of organizational assistance, and the importance of their welfare. Job performance and satisfaction increase with the strengthening of the faith. Consequently, it improves the commitment and loyalty of the members to the organization. According to research (18), increase of organizational support is under some organizational conditions (such as empowerment, etc.) and leads to increasing the sense of belonging to the organization, and thus increasing the job motivation and job satisfaction of members (19). The perceived organizational support, high-performance work practices that are consistent with the concepts of organizational support theory suggests that the organization, in order to maintain its human resources, makes investment in terms of education, empowerment, and rewards, and fosters perceived organizational support that, in turn, leads to an organizational affective emotional commitment (20). Accordingly, organizational support can play a mediating role in the relationship between organizational empowerment and job satisfaction.

Another variable considered in this research as a mediating variable, is organizational justice. Organizational justice as another work-related factors can have a mediating role in these relationships. The assessment of people perceptions of justice and fairness in the workplace is called "organizational justice". In this regard, the researchers also showed that organizational justice has a significant relationship with some job consequences such as job satisfaction and job commitment. These findings indicate that organizational justice can play a mediator role in the relationships between empowerment and job consequences $(21,22)$.

Moreover, organizational innovation is among the other variables related to work-related factors. Organizational innovation refers to the creativity of organizations and employees in achieving organizational goals (23). When employees are innovating in the workplace, and thus provide the organization's growth and development, and this is of interest to managers, they feel managers need their innovation. When people feel that their thoughts are being considered and valued, they feel empathy and empowerment (24).

Therefore, the current research question was whether the job and organizational consequences (organizational citizenship behavior, job performance, organizational commitment, job satisfaction, turnover intention, and absenteeism) of faculty members can be explained based on psychological empowerment as well as the role of mediating the work-related factors (organizational justice, organizational innovation, and organizational support).

In sum, based on what has been stated, the conceptual and theoretical model of the relationship between psychological empowerment and occupational and organizational consequences with the mediating role of jobrelated factors are set as figure 1.

\section{Material and Methods}

The current research was applicable in objective, descriptive in the way of data collection, and correlational in the type; and particularly was based on the path analysis-structural equation modeling. In the analytical model, psychological empowerment was a predictor variable, workrelated factors (organizational support, organizational innovation, and organizational justice) were mediating variables, and job and organizational consequences (organizational citizenship behavior, job performance, job 
satisfaction, organizational commitment, absenteeism, and turnover intention) were criterion variables.

The statistical population of the research were all faculty members of the branches of Islamic Azad
University in West Azerbaijan Province, Iran, in the academic year of 2016-2017 (about 747 people), of which the sample size was considered to be 300 based on the Morgan table.

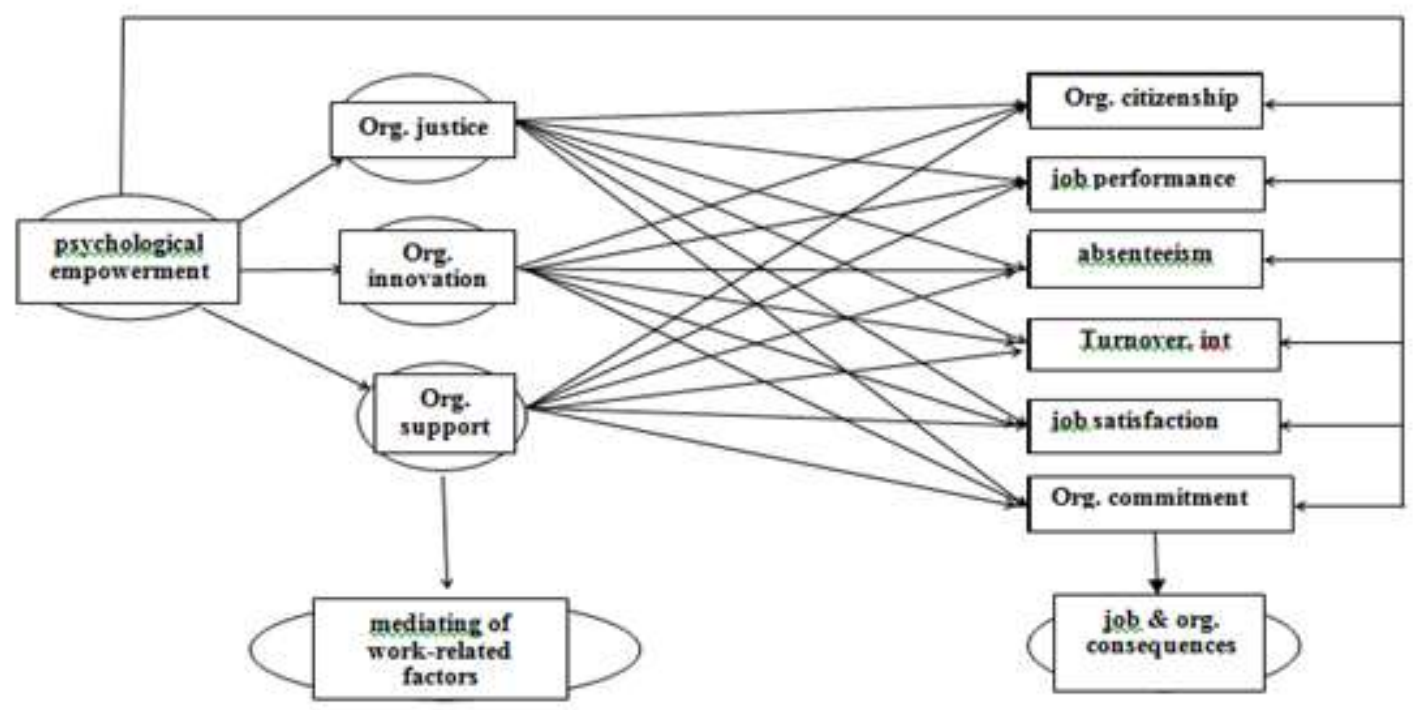

Figure 1: Conceptual model of research

The sampling method was proportionate stratified random method. First, the faculty members were divided into three sections according to the normal division of the province (north, south and center of the province). Then, the number of faculty members in the three regions was calculated. Finally, the number of faculty members from different universities according to the ratios of the different universities of each unit in different cities of each region was obtained according to the sample size. The distribution of questionnaires at the final stage, at university level, was done randomly. In this study, the used data collection tools were a demographic characteristics form (including questions on age, gender, work experience, academic rank, and work experience), nine standard questionnaires, and one researchermade questionnaire as follows (Table 1). It should be noted that all questionnaires are evaluated with a five-point Likert scale with options, $1=$ strongly opposed, 2 = I disagree, $3=$ no opinion, $4=1$ agree, and $5=$ I totally agree.

Table 1: The coefficients of research scales reliability based on Cronbach's alpha

\begin{tabular}{ccc}
\hline Variable & Items & $\begin{array}{c}\text { Cronbach's } \\
\text { alpha }\end{array}$ \\
\hline Psychological empowerment & $1-17$ & 0.82 \\
\hline Organizational support & $18-25$ & 0.71 \\
\hline Organizational innovation & $26-32$ & 0.91 \\
\hline Organizational citizenship \\
behavior & $33-48$ & 0.94 \\
\hline Organizational commitment & $49-63$ & 0.87 \\
\hline Job satisfaction & $64-76$ & 0.78 \\
\hline Turnover intention & $77-85$ & 0.85 \\
\hline Absenteeism & $86-91$ & 0.81 \\
\hline Job performance & $92-108$ & 0.74 \\
\hline Organizational justice & $109-128$ & 0.92
\end{tabular}

Psychological empowerment questionnaire: The 17-questuion psychological empowerment questionnaire of Spritzer, Thomas and Velthouse
(1995) was used to measure psychological empowerment (25). In this questionnaire, for each dimension of psychological empowerment, three 
items are considered, and their responses are based on a 5-point Likert scale from 1 (strongly disagree) to 5 (strongly agree). The questionnaire includes five components of psychological empowerment (competence, meaningfulness, selfefficacy, impact, and trust). Spritzer (1995) determined the reliability of this questionnaire using Cronbach's alpha and retest method. The Cronbach's alpha reliability coefficient was 0.72 in an example of an industrial organization, and 0.62 in the sample of an insurance office; the retest reliability coefficient was reported 0.92 in the sample of the organization, and 0.80 in the sample of the insurance office. Using Cronbach's alpha, the reliability of the questionnaire in this research through its implementation on 30 faculty members, and before its main implementation, was 0.82 .

Organizational support questionnaire: To measure the perceived organizational support, the Rhoades and Eisenberger's perceived organizational support questionnaire was used (26). This questionnaire contains 8 items. Responses are set to a 5-point Likert scale from 1 (strongly disagree) to 5 (strongly agree). Rhoades and Eisenberger reported the validity of this questionnaire by 0.81 using Cronbach's alpha. The reliability of this questionnaire reported by Rhoades and Eisenberger was equal to 0.55 which was found to be significant at $P<0.01$, and this showed that favorable reliability of the questionnaire. Moreover, using Cronbach's alpha, the reliability of the questionnaire in this research through its implementation on 30 faculty members, and before its main implementation, was 0.71 .

Organizational innovation questionnaire: This tool is built on the basis of the standard model of Ana Sano koska (2013), and contains 7 questions. It is based on a 5-point Likert scale from 1 (strongly disagree) to 5 (strongly agree), and has a component too. Biglari in his research reported that the reliability of this tool was 0.84 . To evaluate the validity of the tool, the factor analysis method based on the main components was used in which the model fitting value was at the acceptable level of 0.91 (27).

Organizational citizenship behavior questionnaire: To measure the employee organizational citizenship behavior, the organizational citizenship scale was used. This questionnaire is a modified questionnaire, taken from Smith, Organ, and Near (28), and adapted from the work of the Organ and Konovsky (28). This questionnaire has 16 questions and its responses are on a scale of 5 points from 1 (strongly disagree) to 5 (strongly agree). The questionnaire includes five components of organizational citizenship behavior (altruism, conscience, chivalry, literacy, and civil behavior). Organ and Near, in their study, reported the reliability of this questionnaire between 0.89 to 0.91, through Cronbach's Alpha method. Baharloo et al., in their research, reported the reliability coefficient of this questionnaire 0.66 and 0.79 using Cronbach's and Tensif alpha, respectively. The reliability of the questionnaire in this research through its implementation on 30 faculty members, and before its main implementation, was 0.94 using Cronbach's alpha.

Organizational commitment questionnaire: To determine the level of organizational commitment, Porter's Organizational Commitment Questionnaire (29) was used which consists of 15 questions. This instrument is rated in accordance with the Likert scale of 5 points from 1 (strongly disagree) to 5 (strongly agree). This questionnaire includes three components of organizational commitment (emotional, normative, and continuous). The reliability of the questionnaire in this research through its implementation on 30 faculty members, and before its main implementation, was calculated as 0.87 by using Cronbach's alpha.

Job satisfaction questionnaire: This questionnaire was designed by Linz to measure job satisfaction, and its purpose is to examine and evaluate the job satisfaction of organizations. This questionnaire contains 13 questions, and it is rated in accordance with the Likert scale of 5 points from 1 (strongly disagree) to 5 (strongly agree), and has also a general score without components. The reliability of the job satisfaction questionnaire in research done by Asghari and Hosseini was 0.858 . In addition, in their study to examine the validity of the tool, the main components analysis method was used which the validity of the tool was reported to be acceptable (30). Using Cronbach's alpha, the reliability of the questionnaire in this research through its implementation on 30 faculty members, and before its main implementation, was calculated 0.78 .

Turnover intention questionnaire: In standard turnover intention questionnaire, the two components considered for turnover intention are the feeling of working with the organization (the amount of employee's loyalty, and his/her attention to the organization fate), and the decision to leave the organization (the employee's intention to think of leaving the current job, and looking for a new one). This questionnaire contains 9 questions and it is rated as 5-point Likert scale from 1 (strongly disagree) to 5 (strongly agree). In the research done by Raufi Sangachin, the content validity was used to determine the validity of the questionnaire. The reliability of the questionnaire in this research through its implementation on 30 faculty members, 
and before its main implementation, was calculated as 0.85 by using Cronbach's alpha (31). Absenteeism questionnaire: This was a researcher-made questionnaire and it is a Likert scale of 5 points from 1 (strongly disagree) to 5 (strongly agree). The reliability of the questionnaire in this research through its implementation on 30 faculty members, and before its main implementation, was calculated as 0.81 using Cronbach's alpha. The validity was also reviewed and verified based on content validity through interviews with expert individuals.

Job performance questionnaire: It is a 15-question job performance questionnaire prepared by Paterson and translated by Shakkarshekan and Arshadi in Iran (32). This questionnaire is based on a 5-points Likert scale from 1 (very little) to 5 (very much), and includes four components of job performance (discipline, responsibility, cooperation, and job improvement). To determine the reliability, the Cronbach's alpha coefficient was calculated which was 0.74 for job performance, showing a good reliability of the measurement tool. Organizational justice questionnaire: Colquitt's Organizational Justice Questionnaire (33) has 20 question, and is rated in accordance with Likert 5point scale from 1 (very little) to 5 (very much). This questionnaire which was made by Colquitt has four dimensions as follows: the procedural justice dimension includes questions 109 to 115 , the distributive justice dimension includes questions 161 to 123 , the interpersonal justice dimension includes questions 120 to 123 , and the information justice dimension includes questions 124 to 128 . The reliability of this questionnaire is acceptable. The reliability of the questionnaire in this research through its implementation on 30 faculty members, and before its main implementation, was 0.92 based on Cronbach's alpha.

To analyze the obtained data, Pearson correlation coefficient and structural equation modeling were used. The data were analyzed using descriptive tests in SPSS software (version 20, IBM Corporation, Armonk, NY, USA) as well as software-based structural equations modeling (LIZREL, version 3, Scientific Software International Inc., Skokie, IL, USA).

\section{Results}

In examining of the faculty members gender, from 300 people selected as a sample, 218 (72.7\%) were men and $82(27.3 \%)$ were women. Besides, the data on their work experience, as the research sample, indicated that of the 300 respondents, 98 $(32.6 \%)$ had less than 5 years of experience, 155 $(51.6 \%)$ had between 6 to 15 years, and 47 $(15.6 \%)$ had more than 15 years of experience. The highest frequency was observed in the work experience of 6 to 15 years.

As is shown in table 2, the correlation coefficient between psychological empowerment with the other variables was as 0.38 with organizational support, 0.29 with organizational innovation, 0.52 with organizational citizenship behavior, 0.37 with organizational commitment, 0.34 with job satisfaction, 0.33 with job performance, 0.34 with organizational justice, -0.24 with turnover intention, and -0.31 with absenteeism, and also it was significant at the level of 0.050 . Among the studied variables, the highest correlation was found between psychosocial empowerment of faculty members with organizational citizenship behavior, and the least correlation was found between psychological empowerment with turnover intention.

Table 2: Correlation matrix between research variables

\begin{tabular}{|c|c|c|c|c|c|c|c|c|c|}
\hline Empowerment through & 1 & 2 & 3 & 4 & 5 & 6 & 7 & 8 & 9 \\
\hline Organizational support & 0.38 & 1 & & & & & & & \\
\hline Organizational innovation & 0.29 & 0.61 & 1 & & & & & & \\
\hline $\begin{array}{c}\text { Organizational citizenship } \\
\text { behavior }\end{array}$ & 0.52 & 0.48 & 0.41 & 1 & & & & & \\
\hline Organizational commitment & 0.37 & 0.56 & 0.45 & 0.63 & 1 & & & & \\
\hline Job satisfaction & 0.34 & 0.30 & 0.25 & 0.44 & 0.36 & 1 & & & \\
\hline Job performance & 0.33 & 0.38 & 0.36 & 0.38 & 0.34 & 0.25 & $\overline{1}$ & & \\
\hline Organizational justice & 0.34 & 0.36 & 0.30 & 0.47 & 0.34 & 0.26 & 0.40 & 1 & \\
\hline Turnover intention & -0.24 & -0.23 & -0.23 & -0.26 & -0.22 & -0.18 & -0.20 & -0.27 & 1 \\
\hline Absenteeism & -0.31 & -0.33 & -0.34 & -0.36 & -0.27 & -0.22 & -0.28 & -0.29 & 0.39 \\
\hline
\end{tabular}

* P-value $<0.05$ all correlations are meaningful. 
In order to better understanding of the relationships of empowerment impact of workrelated factors on job and organizational consequences, path analysis-structural equation modeling was used. Findings of this analysis verified the results and indicated the findings from the research hypotheses. According to the output of the software, and as it is understood from the standard estimates and the significant numbers of the path analysis in the research hypotheses shown in table 3 , the values of the fit indices indicated that the model was well-fitted.

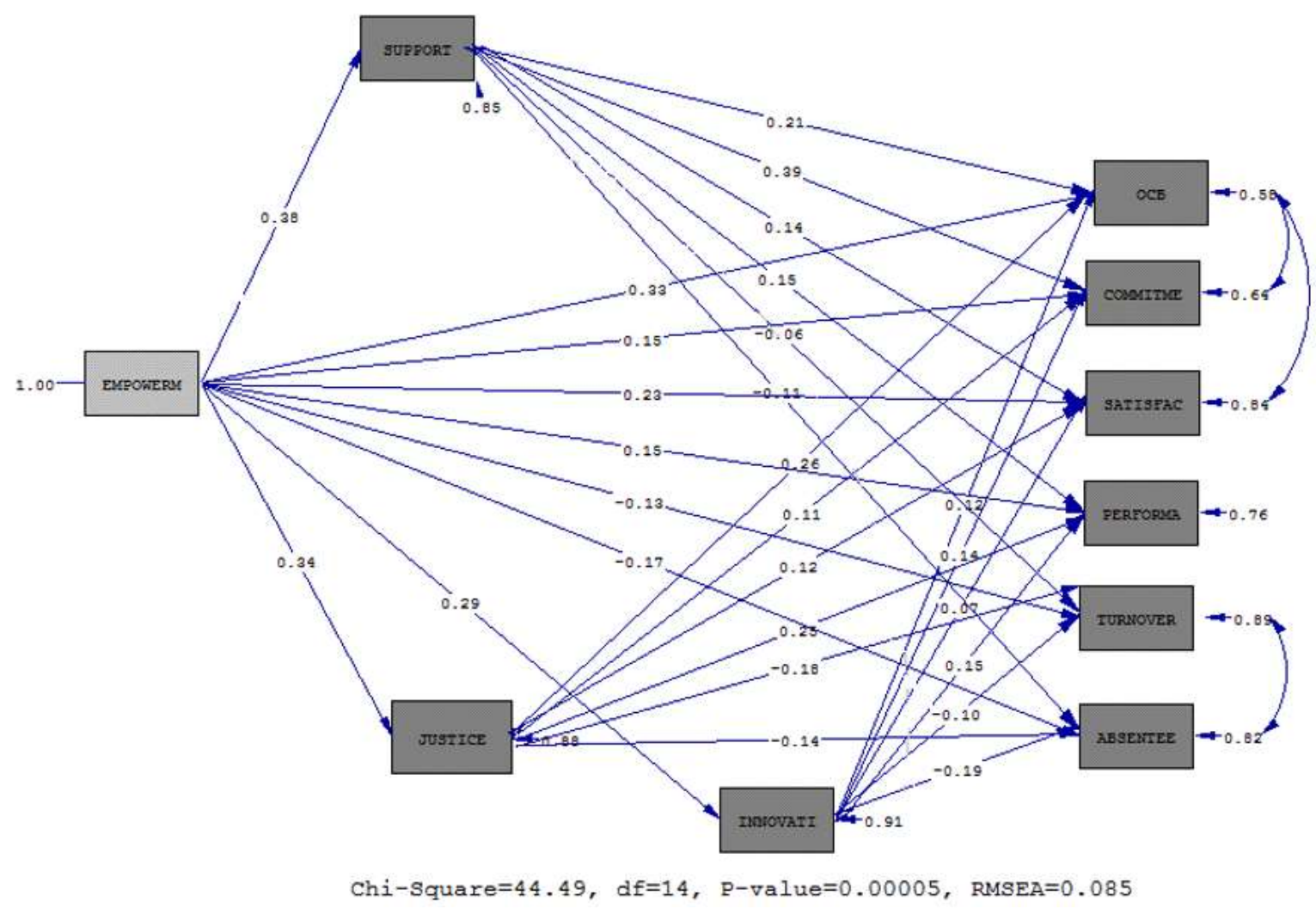

Figure 2: Standard coefficients of structural relationship between research variables

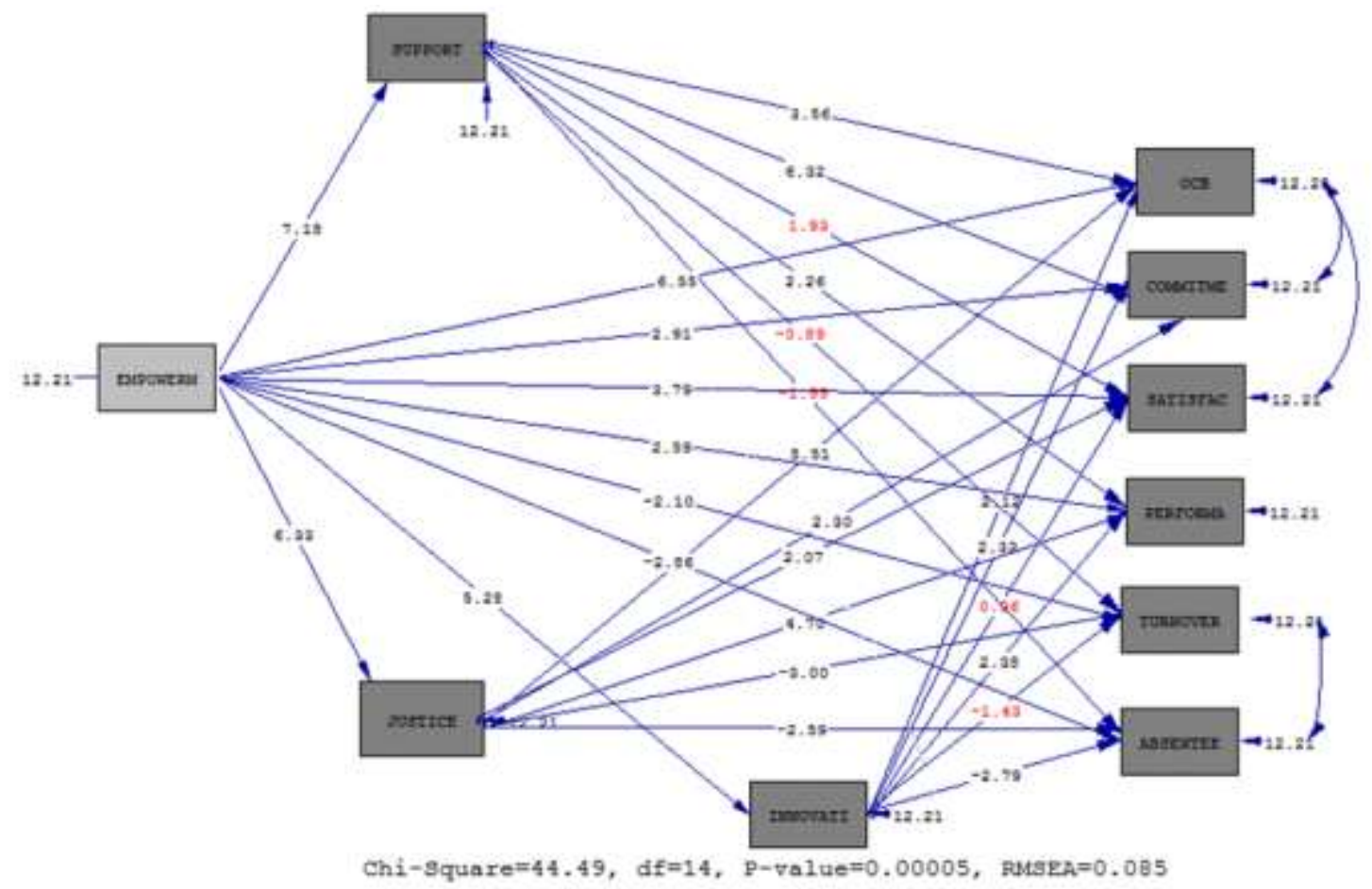

Figure 3: T-coefficients of structural relationship between research variables

One of the features of structural equation modeling is to estimate the direct and indirect effects of variables on each other. This feature allows researchers to examine the mediator role of variables in the model. According to table 3, the direct and indirect effects of empowerment on organizational and occupational consequences, all the paths are significant at the level of 0.001 , and since these paths go through innovation, support, and 
justice, the mediating role of these variables is confirmed in the relationship between occupationalorganizational consequences and psychological empowerment.

Table 3: Estimation of direct effect (DE) and indirect effect (IE) coefficients and mediation review

\begin{tabular}{|c|c|c|c|c|c|}
\hline \multicolumn{3}{|c|}{ Hypothesis with path analysis } & \multirow{2}{*}{$\begin{array}{c}\begin{array}{c}\text { Standard path } \\
\text { coefficient }\end{array} \\
0.022\end{array}$} & \multirow{2}{*}{$\frac{\mathbf{t}}{6.55}$} & \multirow{2}{*}{$\frac{\text { Result }}{\mathrm{DE}}$} \\
\hline $\begin{array}{l}\text { Psychological empowerment } \\
\text { behavior(ocb) }\end{array}$ & $\longrightarrow$ & citizenship & & & \\
\hline Psychological empowerment & $\longrightarrow$ & commitment & 0.015 & 2.91 & $\overline{D E}$ \\
\hline Psychological empowerment & $\longrightarrow$ & satisfaction & 0.023 & 3.79 & $\overline{D E}$ \\
\hline Psychological empowerment & $\longrightarrow$ & performance & 0.015 & 2.59 & $\overline{\mathrm{DE}}$ \\
\hline Psychological empowerment & $\longrightarrow$ & turnover & -0.013 & -2.10 & $\overline{\mathrm{DE}}$ \\
\hline Psychological empowerment & $\longrightarrow$ & absenteeism & -0.019 & -2.86 & $\overline{\mathrm{DE}}$ \\
\hline $\begin{array}{l}\text { Psychological empowerment } \\
\text { \{justice,support,innovation\} }\end{array}$ & & (ocb) & 0.014 & 6.25 & IE \\
\hline $\begin{array}{l}\text { Psychological empowerment } \\
\text { \{justice,support,innovation\} }\end{array}$ & & commitment & 0.023 & 3.18 & IE \\
\hline $\begin{array}{l}\text { Psychological empowerment } \\
\text { \{justice,support,innovation\} }\end{array}$ & & satisfaction & 0.08 & 3.48 & IE \\
\hline $\begin{array}{l}\text { Psychological empowerment } \\
\text { \{justice,support,innovation\} }\end{array}$ & & performance & 0.014 & 5.46 & IE \\
\hline $\begin{array}{l}\text { Psychological empowerment } \\
\text { \{justice,support,innovation\} }\end{array}$ & & turnover & -0.12 & -3.45 & IE \\
\hline $\begin{array}{l}\text { Psychological empowerment } \\
\text { \{justice,support,innovation\} }\end{array}$ & & absenteeism & -0.15 & -4.32 & $\mathrm{IE}$ \\
\hline
\end{tabular}

${ }^{* *} \mathrm{P}$-value $<0.001$ All paths are meaningful

According to table 4, due to the highness of comparative fit index (CFI), normative fitness index (NFI), incremental fitness index (IFI), non-standard fit fitness index (NNFI), good fitness index (GFI)

Table 4: General fitting indices of the tested model

\begin{tabular}{cccc}
\hline Fitting indices & Desirable amount & Value seen & Fit result \\
\hline Chi-square/df & $<3$ & 3 & Fit \\
\hline Comparative fit index (CFI) & $>0.90$ & 0.98 & Fit \\
\hline Normative fitness index (NFI) & $>0.90$ & 0.97 & Fit \\
\hline Incremental fitness index (IFI) & $>0.90$ & 0.98 & Fit \\
\hline Non-standard fit fitness index (NNFI) & $>0.90$ & 0.94 & Fit \\
\hline Good fitness index (GFI) & $>0.90$ & 0.98 & Fit \\
\hline Root mean square error of approximation (RMSEA) & $<0.08$ & 0.08 & Fit \\
\hline
\end{tabular}

\section{Discussion}

The current research was conducted with the purpose of structural modeling of job and organizational consequences of psychological empowerment with mediation of work-related factors among the faculty members of the Islamic Azad Universities in West Azerbaijan Province, and the lowness of the root mean square error of approximation (RMSEA), it can be seen that the structural model has an optimal fit (34). 
satisfaction, organizational commitment, organizational citizenship behavior, and job performance, and decrease in their turnover intention and absenteeism. The gained results are consistent with the results of Safari (35) and Kim (36). Besides, these results corresponded to the results of Gorgi research in which empowerment effect on employee performance was positive in Golestan Province Telecom Company, Iran (37). In addition, the results were consistent with the findings of Alwani et al. (38). The gained positive effect of psychological empowerment on the job satisfaction is also important. Organizations that ignore the importance of psychological empowerment of employees, with increasing risk of negative consequences, such as absence and intent, can reduce job satisfaction and employee performance (39). Therefore, promotion of the sense of psychological empowerment among the staff is a key in increasing satisfaction, commitment, and job performance, and ultimately the appearance of organizational citizenship behavior, and reduction of absenteeism and turnover intention. Some authors $(40,41)$ focusing on organizational empowerment benefits, assume that there is a driving force behind the efforts that empower employees. Global competition and the changing business environment have made organizational changes inevitably necessary to respond to increasing pressures on improving performance.

In particular, organizations are forced to develop and improve in terms of cost control, flexibility, and quality. In fact, organizations can see many improvements in the field of economic performance though measuring the economic benefits of empowerment. This issue will be identified when it is stated with broader categories such as business process reengineering and comprehensive quality management.

In explaining this finding, it can be said that since empowerment is usually accompanied by delegation of authority and power, it will be ended with the freedom of action, and the granting of freedom of action and the exercise of the authority in work will improve the attitude of the people to work; so that to a large extent, they consider themselves as part of work, and their job commitment, satisfaction, performance, and organizational citizenship behavior get increased. In general, familiarity with the predictors needed for each variable can help us to increase the value of the variable by manipulating the amount of the predictors. Therefore, our hypothesis was that psychological empowerment and its benefits increase the incidence of job satisfaction, organizational commitment, organizational citizenship behavior, and job performance, which the gained results confirmed it. Therefore, organizations can take action to increase the level of job satisfaction, organizational commitment, organizational citizenship behavior, and employee performance through psychological empowerment in this field. Because of the importance of education and research, university authorities are inevitably required to maintain and manage a more empowered human resource. Empowered faculty members are recognized as the most important factor in the dynamics of the university. In summary, giving importance to the human resources and empowering them will have positive and beneficial effects.

Data analysis showed that there was a significant and mediating role for work-related factors (organizational support, organizational innovation, and organizational justice) in the relationship between psychological empowerment and occupational and organizational consequences which organizational innovation was as one of the work-related factors to the relationship between psychological empowerment with occupational and organizational consequences. These findings are consistent with conducted studies. Sanchez and Santos (42) concluded that organizational innovation has a mediator role in the relationship between empowerment with job satisfaction and organizational commitment. In addition, empowerment has a significant effect on organizational commitment and job satisfaction. Salehi et al. showed that there was a significant relationship between creativity and empowerment (43). Soltani et al. found that organizational citizenship behavior had a mediator role in the relationship between organizational support and psychological empowerment with job performance (44). Moreover, Zahednejad showed that there was a relationship between organizational justice and psychological empowerment (45). Altahayneh et al. found that all dimensions of organizational justice had a strong and significant relationship with job satisfaction and organizational commitment (46). Thus, the perception of the faculty members of justice increases staff perception of fair behavior, and enhance the level of organizational commitment, job satisfaction, and job performance. Knol and van Linge examined the effect of structural and mental empowerment on nurses and the relationship between mental empowerment and structural empowerment with innovative behavior. They found that nurses who experienced a higher level of mental empowerment tended to be more innovative (47). In this research, psychological empowerment acted as a mediator between structural 
empowerment and innovative behavior. Therefore, the survival of organizations in a complex and competitive economy depends on creativity and innovation, and this, in the group of management and empowerment of human capital, is considered as the most important source of innovation development. Today, organizations need effective and efficient employees to be able to achieve their goals of comprehensive development and growth. In general, the efficiency and effectiveness of organizations depends on the efficiency and effectiveness of human resources in those organizations, hence moving towards the increasing the psychological empowerment, enjoying creative and diligent human resources is of the main tasks of the organizations which seems very necessary.

The gained results of various studies also show that empowerment will increase employee's motivation, power, and self-efficacy; and employees can use their creativity, and choose their own practice of doing work.(48) Therefore, psychological empowerment is one of the variables affecting the creativity of employees, and in organizations, it is necessary to provide the necessary platforms for increasing the psychological empowerment of employees; because with the increase of psychological empowerment, creativity of employees also increases, which makes organizations not to retreat from their other rivals in today's competition world, and to progress. Therefore, in view of the sensitivity of the issue to strengthen this impact, empowerment should be provided with organizational support, innovation, and justice for faculty members in order to influence the promotion of organizational citizenship behavior, performance, and organizational satisfaction and commitment, and reduce the absenteeism and turnover intention.

At the end, it should be noted that both theoretical and research foundations and the present research confirmed the effect of the psychological empowerment on the job and organizational consequences with the mediating role of the workrelated factors. Yet, it is more important to investigate the validity of the tools used to measure the research variables.

Limitations of this research include the lack of cooperation of some faculty members in the implementation and delivery of questionnaires, the existence of a conservative space in organizational environments, and the lack of a dominant research spirit among some faculty members as well as literature.

Little is said about the relationship between research variables and the lack of access to broad theoretical foundations. In spite of the above limitations, a new, excellent. and growing new field of study has been opened up. Psychological empowerment structures are structures that newly introduced in the field of management and psychology. In this regard, some issues can be identified in the context of this article for future research. The following suggestions can add to the richness of further research in this field.

More research is needed to be done in the field of psychological empowerment with the variables of work-related factors by using other tools. It is suggested that other roles of possible moderators and mediator variables be considered in the relationship between psychological empowerment with job and organizational consequences. Moreover, since in our research, the dimensions of psychological empowerment were not considered, it is suggested that future researchers take the dimensions of psychological empowerment into account.

\section{Conclusion}

The most important result of the current study is that psychological empowerment directly and with mediating of organizational innovation, organizational justice, and organizational support, brings with job and organizational consequences including improving organizational citizenship behavior, organizational commitment, job satisfaction, job performance, and reducing turnover intention and absenteeism.

\section{Acknowledgments}

I am really grateful to the all faculty members and authorities the branches of Islamic Azad University in West Azerbaijan Province, Iran, for their helping me in collecting necessary data. This article is adopted from the doctoral dissertation by Amir Hemmati in the Department of Educational Sciences, Tabriz Branch, Islamic Azad University.

\section{Conflict of interest: None declared.}

\section{References}

1. Moradi E, Didehban H. Faculty member's development in medical education: programs, interventions and outcomes. Journal of Urmia Nursing and Midwifery Faculty 2017; 15(1):10-8.

2. Jamali R, Ghazinoory S, Sadeghi M. Plagiarism and ethics of knowledge: evidence from international scientific papers. J Infor Ethics 2014; 23(1):101-110.

3. Fazeli N. A comparative study of Iranian and British academic cultures an anthropological investigation into the inefficiency of Iranian academic education. Iranian Journal of Anthropology 2003; 1(3):93-132. 
4. Maynard MT, Gilson LL, Mathieu JE. Empowerment-fad or fab? A multilevel review of the past two decades of research. Journal of Management 2012; 38(4):1231-81.

5. Mathieu JE, Gilson LL, Ruddy TM. Empowerment and team effectiveness: an empirical test of an integrated model. J Appl Psychol 2006; 91(1):97-108.

6. Uner $S$, Turan $S$. The construct validity and reliability of the Turkish version of Spreitzer's psychological empowerment scale. BMC Public Health 2010; 10:117.

7. Quiñones M, Van den Broeck A, De Witte H. Do job resources affect work engagement via psychological empowerment? A mediation analysis. Revista de Psicología del Trabajo y de las Organizaciones 2013; 29(3):127-34.

8. Jordan G, Miglič G, Todorović I, Marič M. Psychological empowerment, job satisfaction and organizational commitment among lecturers in higher education: comparison of six CEE countries. Organizacija: Journal of Management, Informatics and Human Resources 2017; 50(1):17-32.

9. Ginsburg L, Berta W, Baumbusch J, Rohit Dass A, Laporte A, Reid RC, et al. Measuring work engagement, psychological empowerment, and organizational citizenship behavior among health care aides. Gerontologist 2016; 56(2):e1-11.

10. Cheasakul $U$, Varma P. The influence of passion and empowerment on organizational citizenship behavior of teachers mediated by organizational commitment. Contaduría y Administración 2016; 61(3):422-40.

11. Jaiswal D, Dhar RL. Impact of perceived organizational support, psychological empowerment and leader member exchange on commitment and its subsequent impact on service quality. International Journal of Productivity and Performance Management 2016; 65(1):58-79.

12. Hanaysha J, Tahir PR. Examining the effects of employee empowerment, teamwork, and employee training on job satisfaction. ProcediaSocial and Behavioral Sciences 2016; 219:27282.

13. Degago E. A study on impact of psychological empowerment on employee performance in small and medium scale enterprise sectors. European Journal of Business and Management 2014; 6(27):60-72.

14. Chang LC, Shih $\mathrm{CH}$, Lin SM. The mediating role of psychological empowerment on job satisfaction and organizational commitment for school health nurses: a cross-sectional questionnaire survey. Int $\mathrm{J}$ Nurs Stud 2010; 47(4):427-33.

15. Al-Hosam AAM, Ahmed S, Ahmad FB, Joarder MHR. Impact of transformational leadership on psychological empowerment and job satisfaction relationship: a case of yemeni banking. Binus Business Review 2016; 7(2):109-16.

16. Kim SY, Fernandez S. Employee empowerment and turnover intention in the US federal bureaucracy. American Review of Public Administration 2017; 47(1):4-22.

17. Bester J, Stander MW, Van Zyl LE. Leadership empowering behaviour, psychological empowerment, organisational citizenship behaviours and turnover intention in a manufacturing division. SA Journal of Industrial Psychology 2015; 41(1):1-14.

18. Karatepe OM. High-performance work practices, perceived organizational support, and their effects on job outcomes: Test of a mediational model. International Journal of Hospitality \& Tourism Administration 2015; 16(3):203-23.

19. Garg S, Dhar RL. Extra-role customer service: the roles of Leader-Member Exchange (LMX), Affective Commitment, and psychological empowerment. International Journal of Hospitality \& Tourism Administration 2016; 17(4):373-96.

20. Rhoades L, Eisenberger R. Perceived organizational support: a review of the literature. J Appl Psychol 2002; 87(4):698-714.

21. Virgolino Al, Coelho A, Ribeiro N. The impact of perceived organizational justice, psychological contract, and the burnout on employee performance: the moderating role of organizational support, in the portuguese context. International Journal of Academic Research in Business and Social Sciences 2017; 7(1):241-63.

22. Watcharachatchawan K, Steane P. Organization citizenship behaviour path analysis: justice, trust, satisfaction and commitment. ABAC ODI Journal Vision Action Outcome 2016; 3(1):1-21.

23. Sun LY, Zhang Z, Qi J, Chen ZX. Empowerment and creativity: A cross-level investigation. Leadersh Q 2012; 23(1):55-65.

24. Hassani M, Fathi $S$, Hosseinpour $A$, Ghasemzadeh A. Influence of psychological empowerment on Job performance and personality accountability of the staff of University of Urmia. Journal of Managing Education in Organizations 2014; 3(3):82-65.

25. Spreitzer GM. Psychological empowerment in the workplace: Dimensions, measurement, and validation. Acad Manage J 1995; 38(5):1442-65.

26. Rhoades L, Eisenberger R. Perceived organizational support: a review of the literature. J Appl Psychol 2002; 87(4):698-714.

27. Sankowska A. Relationships between organizational trust, knowledge transfer, knowledge creation, and firm's innovativeness. The Learning Organization 2013; 20(1):85-100.

28. Organ DW, Konovsky M. Cognitive versus affective determinants of organizational citizenship behavior. Journal of Applied Psychology 1989; 74(1):157-64.

29. Mowday RT, Steers RM, Porter LW. The measurement of organizational commitment. Journal of Vocational Behavior 1979; 14(2):22447.

30. Linz SJ. Job satisfaction among Russian workers. Int J Manpow 2003; 24(6):626-52.

31. Raoufi S, Yasir. The Relationship between Employee Perception of Performance Evaluation Policies with Job Satisfaction and Turnover Intention. [MA Thesis]. Rasht: Islamic Azad University; 2014.

32. Arshadi N, Shokrkon H. An Investiga of the relationship between job stress caused by role conflict and role ambiguity with Job Performance and Job Satisfaction, considering the effects of autonomy and group cohesiveness variables, in 
nisoc employees- Ahvaz region. Journal of Educational and Psychology 2007; 14(2):129-48.

33. Colquitt JA, Conlon DE, Wesson MJ, Porter CO, $\mathrm{Ng} \mathrm{KY}$. Justice at the millennium: a metaanalytic review of 25 years of organizational justice research. J Appl Psychol 2001; 86(3):425-45.

34. Hooman HA. Structural equation modeling with LISREL Application. $1^{\text {st }}$ ed. Tehran: SAMT Publication; 2005.

35. Safari S, Omidi A, Sajadi N, Khabiri M. The relationship of psychological empowerment, organizational commitment and organizational citizenship behavior in physical education teachers of Iran high schools. Journal of Sport Management 2016; 8(1):1-23.

36. Kim S. Participative management and job satisfaction: lessons for management leadership. Public Administration Review 2002; 62(2):23141.

37. Gorji MB. Impact study of empowerment on employees' performance. Journal of Industrial Strategic Management (Pajouheshar) 2010; 7(17):38-56.

38. Alvani SM, PourMehdi K, Bagheri $H$. Investigating the relationship between employee empowerment and the performance of the organization of the education department of Guilan province. Management Engineering 2011; 5(43):42-53

39. Conger JA, Kanungo RN. The empowerment process: Integrating theory and practice. Acad Manage Rev 1988; 13(3):471-82.

40. Spreitzer GM, Mishra A. Survivor responses to downsizing: the mitigating effects of trust and empowerment. Los Angeles, California, United States: Southern California Studies Center, University of Southern California; 1997 Sep. 17p.

41. Whetten DA, Cameron KS. Developing management skills. $9^{\text {th }}$ ed. London, England:
Pearson Education; 2015.

42. Santos-Vijande ML, López-Sánchez JA, González-Mieres C. Organizational learning, innovation, and performance in KIBS. Journal of Management \& Organization 2012; 18(6):870904.

43. Salehi M, Gholtash A, Mortazaei $H$. On the relationship of creativity and cooperation to faculty members empowerment (A case study of Marvdasht Islamic Azad University). Quarterly Journal of New Approach in Educational Administration 2013; 4(3):99-116.

44. Soltani I, Sarihi Asfestani R, Abbasi H. The impacts of perceived organizational support and psychological empowerment on job performance: The media effects of organizational citizenship. Journal of Management Studies in Development \& Evaluation 2013; 23(70):209-29.

45. Zahednezhad H, Manoochehri H, Zaghari Tafreshi M, Farokhnezhad Afshar P, Ghanei Gheshlagh R. Relationship between organizational justice and nurses' psychological empowerment. Iran Journal of Nursing 2015; 28(93-94):78-86.

46. Altahayneh ZL, Khasawneh A, Abedalhafiz A. Relationship between organizational justice and job satisfaction as perceived by Jordanian physical education teachers. Asian Soc Sci 2014; 10(4):131-8.

47. Knol J, van Linge R. Innovative behaviour: the effect of structural and psychological empowerment on nurses. J Adv Nurs 2009; 65(2):359-70.

48. Zhang $X$, Bartol $K M$. Linking empowering leadership and employee creativity: the influence of psychological empowerment, intrinsic motivation, and creative process engagement. Acad Manage J 2010; 53(1):107-28. 